\title{
A saúde bucal masculina dos servidores públicos de Marília, São Paulo, Brasil
}

\author{
The oral health of male civil servants from Marília, São Paulo, Brazil
}

La salud oral de los funcionarios públicos varones de Marília, São Paulo, Brasil

\author{
Maria Luiza Freire Marconatto. Faculdade de Medicina de Marília (FAMEMA). malumarconatto@yahoo.com.br (Autora correspondente) \\ Catiane Maria Nogueira. Secretaria Municipal de Saúde de Marília (SP). catianenogueira@yahoo.com.br \\ Caroline Brandão Pires Almeida. Secretaria Municipal de Saúde de Marília (SP). carolalmeida_bass@hotmail.com \\ Sueli Moreira Pirolo. Secretaria Municipal de Saúde de Marília (SP). pirolo@terra.com.br
}

\section{Resumo}

Este estudo aborda a saúde do homem no âmbito do cuidado da saúde bucal na Atenção Primária à Saúde. Tem como objetivo analisar o conhecimento e a adesão masculina aos cuidados de saúde bucal. 0 método utilizado foi um estudo transversal, descritivo, realizado no município de Marília, SP. Amostragem não probabilística por acessibilidade foi utilizada para o tamanho amostral, perfazendo 280 trabalhadores. Para a coleta de dados utilizou-se a técnica de entrevista estruturada. Os dados foram processados pelo programa Epi-Info versão 6.0 e tratados por teste como qui quadrado. Este estudo permitiu compreender as limitações dos homens no cuidar da sua saúde bucal. As variáveis faixa etária, escolaridade e renda familiar, quando associadas às categorias hábitos alimentares, práticas de higiene e conhecimento sobre a saúde bucal, apresentaram alguns resultados significativos $(p<0,05)$. Tais achados sinalizam a necessidade de investimento tanto em ações de promoção da saúde quanto em ações de prevenção de doenças bucais.

\section{Abstract}

This study addresses men's health within the oral health care in Primary Health Care. It aims to analyze the adherence rate to male oral health care. The study was conducted in the municipality of Marilia, state of Sao Paulo, using descriptive methodology. The sample size was calculated based on the total of municipal workers, which indicated a number of 280 workers to be interviewed. The data were collected using a structured interview technique. The data were processed in Epi-Info, version 6.0 and treated as a Chi-square test. This study allows us to understand the limitations of men in taking care of their oral health, since the variables age, education and family income were significantly associated to the categories eating habits, hygiene practices and knowledge on oral health. These findings suggest the need for investment in both health promotion actions and actions to prevent oral diseases.

\section{Resumen}

Este estudio aborda la salud de los hombres en el ámbito del cuidado de la salud oral en la Atención Primaria de la Salud; tiene como objetivo analizar la tasa de conocimiento y adhesión masculina al tratamiento de la salud oral. El método utilizado fue un estudio transversal, descriptivo, llevado a cabo en el municipio de Marília, SP. Se muestrearon los trabajadores municipales por accesibilidad, no probabilísticamente, totalizando 280 trabajadores entrevistados. Se usó la técnica de entrevista estructurada para la recolección de datos; los datos fueron procesados con el programa Epi-Info versión 6.0 y tratados con la prueba de chi-cuadrado. Este estudio permitió comprender las limitaciones de los hombres en el cuidado de su salud oral. Las variables edad, educación e ingresos familiares, quando relacionadas con hábitos alimentarios, prácticas de higiene y conocimientos sobre salud bucal presentaron algunos resultados significativos $(p<0,05)$. Estos resultados sugieren la necesidad de invertir tanto en acciones de promoción de la salud como en acciones de prevención de las enfermedades orales.

\section{Keywords:}

Men's Health Oral Health Health Promotion Primary Health Care

\section{Palabras clave:}

Salud del Hombre Salud Bucal Promoción de la Salud Atención Primaria de la Salud 


\section{Introdução}

Este estudo aborda a saúde bucal masculina na Atenção Primária à Saúde (APS) tendo em vista a vulnerabilidade dos homens quanto a morbidades passíveis de prevenção. Políticas públicas têm preconizado a APS como porta de entrada preferencial do Sistema Único de Saúde e a saúde bucal como área prioritária, com finalidade de proporcionar à população serviços de promoção, prevenção, cura e reabilitação, em conformidade ao princípio da universalidade, que institui o acesso à saúde para todos, independentemente de sexo ou faixa etária ${ }^{1}$.

A masculinidade e a saúde interagem, numa complexa teia de relaçốes e dimensôes, entre si: os homens na sua singularidade, a organização dos serviços no atendimento às especificidades masculinas e o vínculo estabelecido entre eles e os serviços ${ }^{2}$. Fatores percebidos como desafiadores para inserção dos homens em práticas de saúde estão relacionados com a atribuição à mulher da responsabilidade pelo cuidado à saúde, com o contexto do atendimento na APS (tempo de espera) e também com a não disponibilidade de programas direcionados especificamente à população masculina ${ }^{3}$.

Geralmente, o público masculino pouco se envolve nesse processo que implica em responsabilidade ética e cidadã para cuidar de si mesmo e dos que estáo ao seu redor. A possibilidade do gênero masculino nunca ter visitado o dentista é de $20 \%{ }^{4}$. Por sua vez, o atual modelo de atenção à saúde bucal reflete ainda a prática odontológica curativa hegemônica, voltada para sinais e sintomas das doenças bucais mais prevalentes, como cárie dentária e doença periodontal ${ }^{5}$, apesar das ações de promoção à saúde bucal introduzidas pela Política Nacional de Saúde Bucal, de $2004^{5}$.

Entende-se que a promoção da saúde bucal está relacionada às práticas de higiene, alimentação saudável e conhecimento a respeito. Para a prática de higiene, preconiza-se a remoção do biofilme dental por meios mecânicos e químicos: escovação associada a creme dental/enxaguante e uso do fio dental para remover o biofilme localizado na região interproximal ${ }^{6}$.

Quanto à escovação, recomenda-se sua realização após cada uma das refeições, com ênfase na última do dia, antes de dormir $^{7}$. Estima-se que, em média, a escova deva ser substituída a cada 3 meses, mas como seu desgaste varia, o período de substituição deve ser determinado individualmente ${ }^{8}$. A cabeça da escova deve ser pequena e com arredondamento da extremidade ativa para não traumatizar dentes e gengivas; as cerdas devem ter rigidez suficiente para remoção da placa bacteriana, porém devem ser macias?.

A limpeza da língua diminui a formação bacteriana nas porçóes posteriores, onde normalmente se concentra grande quantidade de saburra, muito pouco alcançada pelas escovas de dente ${ }^{10}$. A utilização de limpadores linguais reduz significativamente os níveis de leveduras na cavidade bucal ${ }^{11}$.

Uma alimentação saudável para a saúde bucal está associada ao consumo diário de 4 porçôes no mínimo e 5 no máximo de verduras/legumes, 3 porçôes no mínimo e 5 no máximo de frutas cítricas/não cítricas e de no mínimo 1 porção e no máximo 2 porçóes de açúcares, doces e refrigerantes ${ }^{12}$. Verduras frescas, cereais, leite, ovos, carne e derivados não provocam cárie. Porém, a ingestão de alimentos com açúcares deve ser seguida pela escovação, pois rapidamente haverá a fermentação e o aparecimento das cáries dentárias ${ }^{13}$.

A ausência de vitaminas causa vários problemas para os dentes e demais tecidos da boca: vitamina A auxilia na formação do esmalte do dente, vitamina $\mathrm{D}$ na constituição dos ossos e dentes, vitamina $\mathrm{K}$ interfere na coagulação do sangue, vitamina $\mathrm{C}$ previne hemorragia na gengiva e vitaminas do complexo B são essenciais na prevenção de algumas doenças da boca ${ }^{13}$.

Há necessidade de estudos que qualifiquem a prática profissional para a promoçáo da saúde, tanto no Brasil como no exterior, pois são mais frequentes pesquisas sobre conhecimento popular e prática cotidiana, ou direcionadas para grupos específicos, como diabéticos e idosos.

Este estudo tem como objetivo analisar a influência das variáveis sociais e econômicas na saúde bucal de homens servidores públicos do município de Marília, SP, para reconhecer a singularidade masculina quanto às limitaçôes e potencialidades relacionadas ao autocuidado. 


\section{Método}

Trata-se de estudo transversal, descritivo, aprovado pelo Comitê de Ética em Pesquisa da Faculdade de Medicina de Marília sob protocolo n. 208/09 e que para ser desenvolvido nas dependências das secretarias municipais obteve anuência do prefeito municipal.

Utilizou-se amostragem não probabilística por acessibilidade para o tamanho amostral, devido à dinâmica do mundo do trabalho, tais como férias, folgas e afastamentos. A amostra se constituiu de 280 trabalhadores das secretarias municipais do gênero masculino na faixa etária de 25-59 anos presentes no local de trabalho no momento da entrevista e que aceitaram participar do estudo. O total de servidores municipais homens encontrados nessa faixa etária foi de 1.538 .

Para a coleta de dados, os responsáveis pelos setores administrativos municipais foram esclarecidos acerca da proposta do estudo. As entrevistas foram realizadas nos locais de trabalho, em horários estabelecidos pelas chefias. Os trabalhadores que participaram da pesquisa receberam esclarecimentos sobre o objetivo e o método utilizado e assinaram termo de consentimento livre e esclarecido.

A técnica de entrevista estruturada foi utilizada para coleta de dados, a qual se orientou por um instrumento elaborado pelas pesquisadoras contendo questôes de identificação, hábitos alimentares (consumo de doces, refrigerantes, sucos, frutas, verduras e legumes), hábitos de higiene (escovaçáo dos dentes, tipo de escova dental, periodicidade de troca da escova, uso do fio dental/enxaguante bucal, escovação da língua e uso de prótese dentária) e questôes sobre conhecimento de saúde bucal (consulta odontológica, conhecimento sobre cárie dentária, alteraçôes bucais com repercussão sistêmica, uso individual da escova e realização do autoexame oral).

Esse instrumento foi submetido a teste piloto nas Unidades de Saúde da Família, o que permitiu adequação quanto à linguagem e quanto a não ser autoaplicável, em função do tempo para responder e da dificuldade de compreensão dos assuntos referentes à saúde bucal dos homens. Os entrevistadores foram entáo capacitados para realização da coleta de dados.

Os dados foram processados pelo programa Epi-Info versão 6.0 e tratados por testes estatísticos, buscando associação entre as seguintes variáveis: idade, escolaridade e renda familiar com as categorias hábitos de higiene, consumo de alimentos e conhecimento sobre saúde bucal. As variáveis foram assim definidas: 1) escolaridade (grau de instrução) correspondente à informaçáo do entrevistado; 2) renda familiar (remuneraçáo média da família) correspondente ao ano de 2009, expressa em salários mínimos; 3) Idade (faixa etária), no ano de 2009.

\section{Resultados}

Os entrevistados foram identificados quanto às características: faixa etária, renda familiar, escolaridade, religião, procedência e estado civil, apresentadas no Quadro 1.

No perfil sociodemográfico dos entrevistados observou-se que: $83,8 \%$ dos homens eram casados; $38,8 \%$ estavam na faixa etária de 40-49 anos e 59\% na faixa etária $<40$ anos; 35,8\% tinham ensino médio e 29,7\%, ensino superior; 62,7\% possuíam renda familiar de 2-3 salários mínimos. Houve predomínio de homens católicos, procedentes de Marília, sendo que a religiâo influenciava muito na vida deles. Quanto ao tipo de ocupação, desempenhavam diversas funçóes no serviço público. A população estudada apresentou número reduzido de homens analfabetos e, portanto, esse segmento não foi utilizado para análise estatística.

O Quadro 2 apresenta que: 28,7\% dos homens faziam uso diário de fio dental, 44,8\% nunca usavam enxaguantes bucais e $25,6 \%$ nunca escovavam a língua, embora $74,4 \%$ escovassem a língua pelo menos uma vez por dia e $59 \%$ escovassem os dentes pelo menos 3 vezes por dia. Escovas de cerdas macias eram utilizadas por 39,8\%. O consumo de frutas/verduras predominou em relação ao consumo de refrigerantes/doces, porém somente $24,7 \%$ consumiam diariamente frutas/verduras. A maioria dos entrevistados relatou que cárie não é uma doença transmissível, 64,2\% não haviam procurado o dentista no período de 1 ano e 55,7\% não realizavam autoexame bucal. Entretanto, 92,5\% faziam uso individual da escova dental e $71,3 \%$ compreendiam que problemas bucais podem causar repercussão sistêmica.

Observou-se associação significativa quanto ao não uso de fio dental nas variáveis: a) faixa etária: entre 20-29 anos $(7,2 \%)$, entre $40-49$ anos $(55,5 \%)(p=0,000)$ e na faixa etária $\geq 50$ anos $(50 \%)$; b) na escolaridade: $21,8 \%$ entre aqueles 
Quadro 1. Características sociodemográficas dos trabalhadores municipais de Marília,SP, em 2009.

\begin{tabular}{|c|c|c|c|}
\hline \multicolumn{2}{|c|}{ Variáveis } & $\mathrm{N}^{0}$ & $\%$ \\
\hline \multirow[t]{4}{*}{ Faixa etária } & 20-29 anos & 84 & 29,9 \\
\hline & 30-39 anos & 82 & 29,1 \\
\hline & 40-49 anos & 108 & 38,8 \\
\hline & $\geq 50$ anos & 6 & 2,2 \\
\hline \multirow[t]{2}{*}{ Procedência } & Marília & 190 & 67,7 \\
\hline & Outras cidades & 90 & 33,3 \\
\hline \multirow[t]{3}{*}{ Religião } & Católica & 177 & 63,1 \\
\hline & Evangélica & 62 & 22,2 \\
\hline & Nenhuma & 23 & 8,2 \\
\hline \multirow[t]{3}{*}{ Influência da religião } & Muita & 145 & 52,0 \\
\hline & Pouca & 81 & 29,0 \\
\hline & Não influencia & 54 & 19,0 \\
\hline \multirow[t]{4}{*}{ Escolaridade } & Analfabeto & 4 & 1,5 \\
\hline & Fundamental & 92 & 32,9 \\
\hline & Médio & 100 & 35,8 \\
\hline & Superior & 84 & 29,7 \\
\hline \multirow[t]{2}{*}{ Estado civil } & Juntos $^{1}$ & 234 & 83,8 \\
\hline & Separados $^{2}$ & 46 & 16,2 \\
\hline \multirow[t]{3}{*}{ Faixa de renda em salários mínimos } & Até 1 & 32 & 11,1 \\
\hline & $2-3$ & 175 & 62,7 \\
\hline & $\geq 3$ & 73 & 26,2 \\
\hline \multirow[t]{3}{*}{ Ocupação } & Serviços gerais & 92 & 33,0 \\
\hline & Técnico administrativo & 33 & 11,8 \\
\hline & Outras ocupações & 155 & 55,2 \\
\hline
\end{tabular}

'homens casados e em união estável; ${ }^{2 h o m e n s ~ s o l t e i r o s, ~ v i u ́ v o s ~ e ~ d i v o r c i a d o s . ~}$

que tinham ensino fundamental quando comparados aos $12,4 \%$ com ensino superior $(\mathrm{p}=0,000)$. A renda não registrou significância estatística com o náo uso de fio dental, sendo que 32,2\% dos trabalhadores de menor renda não usavam fio dental, enquanto 44,1\% daqueles com maior renda também não o utilizavam ( $\mathrm{p}=0,17)$.

Identificou-se significado estatístico entre a escovação dos dentes na frequência de $0-2$ vezes/dia e as seguintes variáveis: a) faixa etária: entre 20-29 anos (22,8\%) quando comparada a faixa $\geq 50$ anos (83,3\%) ( $\mathrm{p}=0,005)$; b) escolaridade: 49,9\% entre trabalhadores com ensino fundamental, comparados com $32 \%$ entre aqueles com ensino superior $(\mathrm{p}=0,000)$. No entanto, a variável renda não apresentou significância estatística com relação a escovaçáo diária, alcançando $45,1 \%$ entre trabalhadores de menor renda versus 27,8\% entre aqueles com maior renda ( $\mathrm{p}=0,97$ ) (Quadro 3).

O não uso de enxaguantes bucais obteve associação significativa nas variáveis escolaridade: $53,1 \%$ entre os trabalhadores com ensino fundamental versus $35 \%$ entre os que tinham ensino superior ( $\mathrm{p}=0,000)$; faixa etária: entre $31,3 \%$ dos homens com 20-29 anos versus 58,3\% entre aqueles com 40-49 anos ( $\mathrm{p}=0,04$ ); e renda: entre 41,9\% dos homens com menor renda versus os $83,3 \%$ daqueles com maior renda $(\mathrm{p}=0,01)$. As variáveis faixa etária e renda apresentaram maior prevalência, com significado estatístico.

A não escovação da língua foi estatisticamente significativa quando comparada a escolaridade e idade: a) escolaridade: não escovavam a língua 40,2\% dos homens com ensino fundamental, comparados a 17,8\% dos homens com ensino superior $(\mathrm{p}=0,000)$; b) faixa etária: $13,2 \%$ dos homens entre 20-29 anos não escovavam a língua versus $50 \%$ dos homens $\geq 50$ anos $(\mathrm{p}=0,037)$. Entretanto, na variável renda observou-se que não escovavam a língua $35,4 \%$ dos homens com menor renda, comparados a $67,4 \%$ daqueles com maior renda $(\mathrm{p}=0,94)$, o que não configura significância estatística.

Associação estatística foi observada no uso de prótese quanto à faixa etária e escolaridade, pois $9,6 \%$ dos homens entre 20-29 anos faziam uso de prótese versus $83,3 \%$ daqueles na faixa $\geq 50$ anos $(\mathrm{p}=0,000)$. Já a variável escolaridade mostrou que utilizavam prótese dentária $25,5 \%$ dos trabalhadores com ensino fundamental comparados a 9,8\% daqueles com ensino superior ( $\mathrm{p}=0,02)$; e $32,7 \%$ dos homens com menor renda tinham prótese dentária versus $28,8 \%$ daqueles com maior renda. 
Quadro 2. Hábitos de higiene, hábitos alimentares e conhecimento sobre saúde bucal dos trabalhadores municipais de Marília, SP, em 2009.

\begin{tabular}{|c|c|c|c|c|}
\hline \multirow{2}{*}{$\frac{\text { Hábitos de higiene }}{\text { Escovação dentária/dia }}$} & \multicolumn{4}{|c|}{$\%$} \\
\hline & Nunca & $1-2$ & $3-4$ & $\geq \mathbf{5}$ \\
\hline & 4,7 & 34,8 & 43,4 & 14,3 \\
\hline \multirow[t]{2}{*}{ Tipo de escova } & Macia & Média & Dura & Extra macia \\
\hline & 39,8 & 27,2 & 13,6 & 13,3 \\
\hline \multirow[t]{2}{*}{ Troca de escova/mês } & 1 & 2 & 3 & $>3$ \\
\hline & 14,0 & 31,9 & 33,0 & 17,9 \\
\hline \multirow[t]{2}{*}{ Uso de fio dental/semana } & Nunca & Diário & $1 S^{*}$ & $4 S^{*}$ \\
\hline & 31,5 & 28,7 & 16,5 & 12,9 \\
\hline \multirow[t]{2}{*}{ Uso de enxaguante bucal/semana } & Nunca & Diário & $1 S^{*}$ & $4 S^{*}$ \\
\hline & 44,8 & 17,2 & 17,2 & 12,5 \\
\hline \multirow[t]{2}{*}{ Escovação da língua/dia } & Nunca & 1 a 2 & 3 a 4 & $>5$ \\
\hline & 25,6 & 36,1 & 20,2 & 10,5 \\
\hline \multicolumn{5}{|l|}{ Hábitos alimentares } \\
\hline \multirow[t]{2}{*}{ Consumo doce/semana } & Nunca & Diário & $1 S^{*}$ & $4 S^{*}$ \\
\hline & 9,0 & 7,9 & 51,6 & 19,4 \\
\hline \multirow[t]{2}{*}{ Consumo de frutas e verduras/semana } & Nunca & Diário & $1 S^{*}$ & $4 S^{\star}$ \\
\hline & 1,8 & 24,7 & 21,9 & 33,7 \\
\hline \multirow[t]{2}{*}{ Consumo de refrigerantes/semana } & Nunca & Diário & $1 S^{*}$ & $4 S^{*}$ \\
\hline & 6,5 & 17,6 & 36,6 & 25,4 \\
\hline Conhecimento sobre saúde bucal & \multicolumn{2}{|c|}{ Sim } & \multicolumn{2}{|c|}{ Não } \\
\hline Cárie é transmissível & \multicolumn{2}{|c|}{47,3} & \multicolumn{2}{|c|}{52,7} \\
\hline Uso individual da escova & \multicolumn{2}{|c|}{92,5} & \multicolumn{2}{|c|}{07,5} \\
\hline Realiza autoexame bucal & \multicolumn{2}{|c|}{44,3} & \multicolumn{2}{|c|}{55,7} \\
\hline Presença de cárie & \multicolumn{2}{|c|}{68,5} & \multicolumn{2}{|c|}{31,5} \\
\hline Procura o dentista no ano & \multicolumn{2}{|c|}{35,8} & \multicolumn{2}{|c|}{64,2} \\
\hline Problemas bucais causam repercussão sistêmica & \multicolumn{2}{|c|}{71,3} & \multicolumn{2}{|c|}{28,7} \\
\hline
\end{tabular}

*1S significa 1 vez na semana; 4S significa 4 vezes na semana.

Quadro 3. Hábitos de higiene segundo faixa etária, escolaridade, renda e estado civil dos trabalhadores municipais de Marília, SP, em 2009.

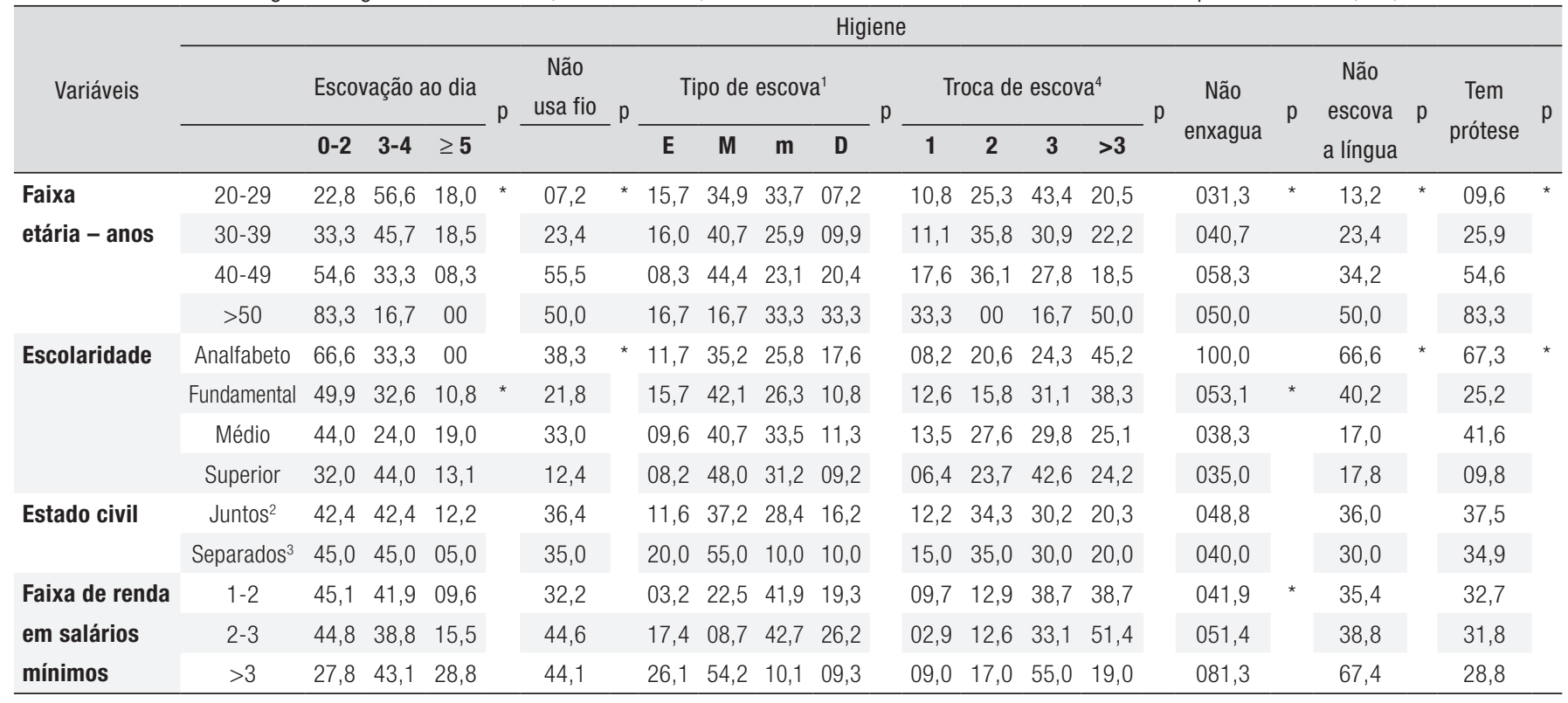

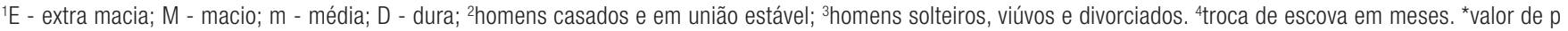
com significância estatística. 
O tipo de escova não obteve significância estatística: a) 40,4\% dos trabalhadores na faixa etária de 40-49 anos utilizavam escova macia contra $16,7 \%$ dos homens na faixa de $\geq 50$ anos. Já quanto à escolaridade, $42,1 \%$ dos que tinham ensino fundamental utilizavam escova macia contra $48 \%$ dos trabalhadores com ensino superior. Com relaçáo a renda: $22,5 \%$ dos trabalhadores com menor renda utilizavam escova macia quando comparados a 54,2\% daqueles com maior renda $(\mathrm{p}=0,17)$.

Não houve associação significativa na frequência de troca de escova, pois 43,3\% dos homens na faixa etária de 20-29 anos trocavam a escova a cada 3 meses contra $16,7 \%$ dos homens da faixa $\geq 50$ anos ( $\mathrm{p}=0,18)$. Entretanto, no item escolaridade, $38,3 \%$ dos trabalhadores com ensino fundamental trocavam-na com intervalo maior que 3 meses contra $24,2 \%$ dos trabalhadores com ensino superior. Com relação a renda: $55 \%$ dos homens com maior renda trocavam de escova a cada 3 meses quando comparados aos $38,7 \%$ dos trabalhadores com menor renda $(\mathrm{p}=0,64)$.

A variável estado civil não obteve significância estatística quanto a hábitos de higiene bucal e apresentou frequência reduzida de homens separados, assim, 42,4\% dos homens casados ou com união estável escovavam os dentes 3-4/dia, 36,4\% não usavam fio dental, 37,2\% utilizavam escovas macias, 34,3\% trocavam a escova a cada 2 meses, 48,8\% não faziam uso de enxaguantes, $36 \%$ não escovavam a língua e 37,5\% tinham prótese dentária.

O consumo de doces apresentou significância estatística somente na variável idade, com maior prevalência na faixa etária $\geq 50$ anos, com $50 \%$ dos homens consumindo mais de 5 vezes por semana, em contraste com $24 \%$ dos de $20-29$ anos $(\mathrm{p}=0,010)$. Para a escolaridade, $5,7 \%$ dos homens com ensino fundamental não consumiam doce quando comparados com $7,6 \%$ daqueles com ensino superior $(\mathrm{p}=0,13)$. No item renda, $61,2 \%$ dos trabalhadores com menor renda consumiam $1-2$ vezes doce na semana versus $48,3 \%$ daqueles com renda maior ( $\mathrm{p}=0,39)$ (Quadro 4).

Quanto ao consumo de refrigerantes, obteve-se significância estatística: 25,9\% dos homens entre 40-49 anos consumiam refrigerantes mais de 4 vezes na semana contra $66,7 \%$ daqueles da faixa $\geq 50$ anos ( $p=0,017$ ); 22,8\% dos homens com ensino fundamental consumiam refrigerante mais de 4 vezes/semana em contraste com 19,1\% daqueles com ensino superior $(\mathrm{p}=0,29)$; $35,4 \%$ daqueles com baixa renda, por sua vez, consumiam refrigerantes mais de 4 vezes/semana, comparados com 33,3\% dentre os de maior renda $(\mathrm{p}=0,07)$.

O consumo diário de frutas/verduras mostrou que 25,9\% dos homens entre 40-49 anos consumiam frutas/verduras, mais de 5 vezes/semana em relação a $66,7 \%$ dos entrevistados na faixa $\geq 50$ anos ( $p=0,32) ; 31,4 \%$ com ensino fundamental consumiam frutas/verduras mais de 5 vezes/semana, comparados aos $50 \%$ dos entrevistados com ensino superior $(\mathrm{p}=0,23)$; assim como $43 \%$ dos homens com maior renda consumiam frutas/verduras mais de 5 vezes/semana versus $35,4 \%$ daqueles com menor renda $(\mathrm{p}=0,54)$.

Houve associação significativa entre ter cárie, faixa etária e escolaridade: 77,1\% dos homens de 20-29 anos tiveram cárie quando comparados com $16,7 \%$ dos homens $\geq 50$ anos ( $\mathrm{p}=0,002) ; 71,4 \%$ daqueles com ensino fundamental tiveram cárie, em contraste com $67,3 \%$ dos entrevistados com ensino superior $(\mathrm{p}=0,000)$. O nível de renda náo apresentou significância estatística, apenas mostrou que $11,1 \%$ dos homens com ensino superior tiveram cárie $(\mathrm{p}=0,4)$.

Quadro 4. Hábitos alimentares segundo faixa etária, escolaridade, renda e estado civil dos trabalhadores municipais de Marília, SP, em 2009.

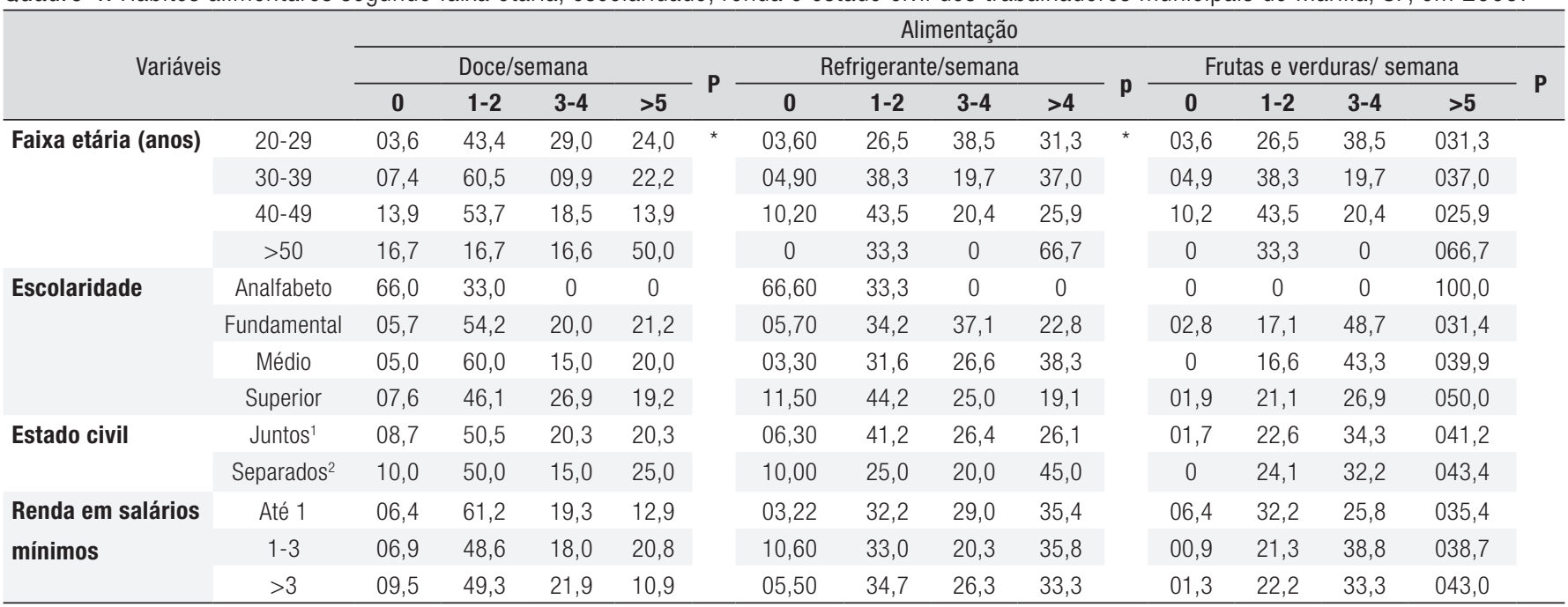

${ }^{1}$ homens casados e em união estável; ${ }^{2 h}$ homens solteiros, viúvos e divorciados; *valor de p com significância estatística. 
A compreensão da cárie como doença não transmissível foi observada tanto na faixa etária de 20-29 anos (42,1\%) quanto na de $\geq 50$ anos $(59,7 \%)(p=0,29)$. O mesmo aconteceu quanto à escolaridade: essa compreensão registrou-se para 57,6\% dos entrevistados com ensino fundamental e para 48,6\% dos que tinham ensino superior ( $\mathrm{p}=0,647)$; assim como para 58\% dos entrevistados com menor renda e para 58,6\% daqueles com maior renda ( $\mathrm{p}=0,29)$ (Quadro 5).

Não houve significância estatística quanto ao uso individual da escova, que predominou em 96,3\% na faixa etária de 20-29 anos e em 89,3\% na faixa $\geq 50$ anos ( $\mathrm{p}=0,26$ ); $93 \%$ dos homens com ensino fundamental e $96 \%$ dos entrevistados com ensino superior faziam uso individual da escova $(\mathrm{p}=0,139)$. Entre os entrevistados de menor renda, $100 \%$ faziam uso de escova, enquanto entre os de maior renda $88,5 \%$ usavam escova dental individualmente ( $\mathrm{p}=0,26$ ).

Realizar autoexame bucal não obteve associação significativa. Ela prevaleceu na faixa etária entre 20-29 anos (39,8\% dos homens) e na faixa $\geq 50$ anos ( $66,7 \%$ dos homens) ( $\mathrm{p}=0,34)$, mas houve resultado clinicamente significativo, que pode associa-se às políticas de prevenção do câncer bucal. Para escolaridade e renda não houve praticamente diferença, nem associação estatística. Quanto à escolaridade, $51 \%$ dos entrevistados com ensino fundamental e 53,8\% dos com ensino superior faziam o autoexame ( $\mathrm{p}=0,682)$. Com relação ao nível de renda, $58 \%$ daqueles com menor renda e $62,2 \%$ daqueles com maior renda referiram fazer o autoexame oral $(\mathrm{p}=0,27)$.

Não houve significância estatística quanto ao conhecimento de problemas bucais com repercussão sistêmica, sendo que prevaleceram 67,5\% entre homens na faixa 20-29 anos e 84,3\% entre os da faixa $\geq 50$ anos ( $\mathrm{p}=0,15)$. Quanto à escolaridade, $71,9 \%$ dos entrevistados com ensino fundamental e 79,6\% daqueles com ensino superior pontuaram os problemas bucais causando repercussáo sistêmica $(\mathrm{p}=0,07)$, o mesmo aconteceu para $77,4 \%$ dos entrevistados com menor renda e $69,4 \%$ daqueles com maior nível de renda $(\mathrm{p}=0,08)$.

Em relaçáo à procura por dentista em 1 ano, não houve associação estatística com relaçáo a escolaridade e nível de renda, mas quanto a faixa etária houve associação significativa. Assim, prevaleceram 83,1\% dos homens de 20-29 anos e 83,3\% dos na faixa $\geq 50$ anos que procuraram o dentista em 1 ano ( $\mathrm{p}=0,01) ; 79,3 \%$ daqueles com ensino fundamental e 77,9\% dos entrevistados com ensino superior $(\mathrm{p}=0,91) ; 70,8 \%$ dos servidores que tinham menor renda e $76,3 \%$ daqueles com maior renda $(\mathrm{p}=0,46)$.

A variável estado civil não obteve significado estatístico quanto ao conhecimento sobre saúde bucal: o que prevaleceu para os casados foi que 50,5\% não consideravam a cárie transmissível, em contraste com $65 \%$ dos separados; $66,8 \%$ dos casados já haviam tido cárie, comparados aos $77,4 \%$ dos separados; $91,8 \%$ dos casados faziam uso individual da escova, versus praticamente igual número dos separados; $52,9 \%$ dos casados realizavam autoexame oral, contra $60 \%$ dos separados; $77,3 \%$ dos casados consideravam que problemas bucais têm repercussão sistêmica em contraste com 59,6\% dos separados; e 40,1\% dos casados procuraram o dentista em 1 ano, número praticamente igual à prevalência entre separados/solteiros.

Quadro 5. Conhecimento sobre saúde bucal segundo faixa etária, escolaridade, renda e estado civil dos trabalhadores municipais de Marília, SP, em 2009.

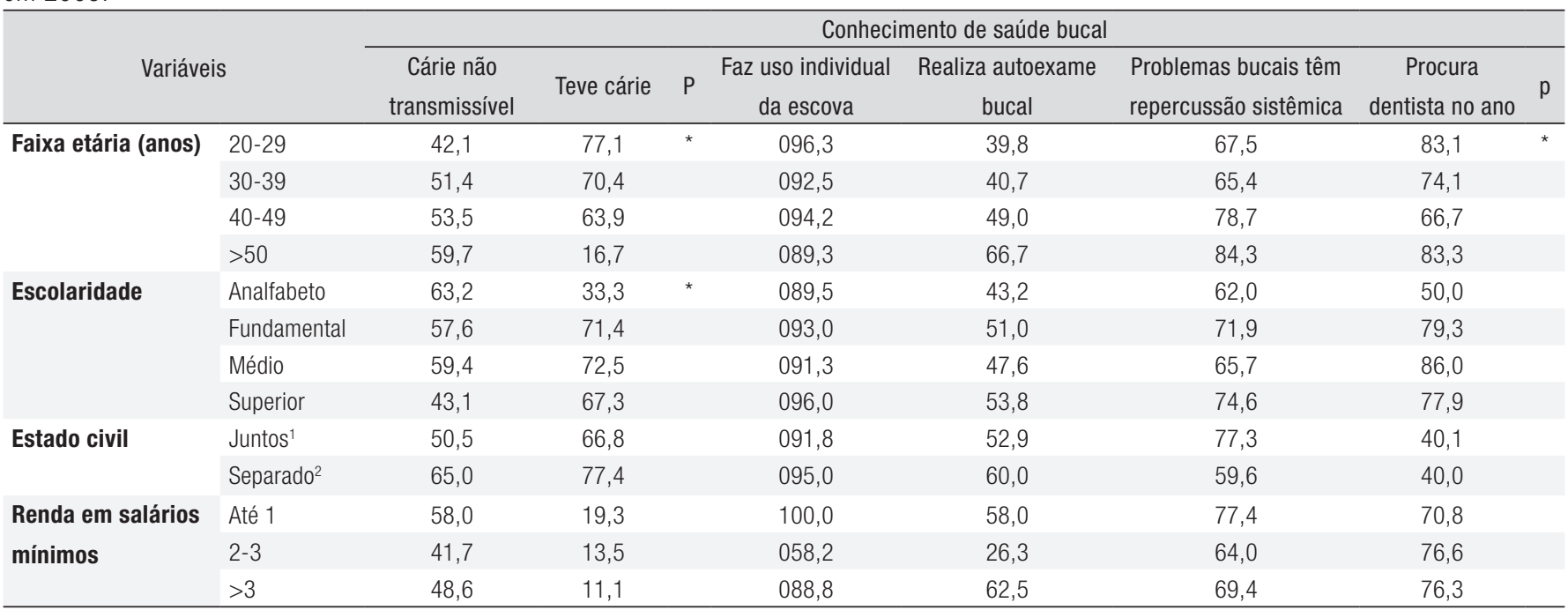

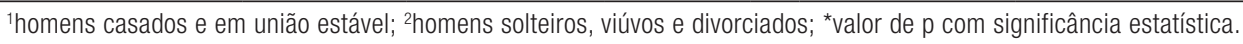




\section{Discussão}

Os servidores municipais do sexo masculino com baixa escolaridade e maior idade mostraram uma prática de higiene bucal limitada: baixa frequência da escovação dentária, de uso do fio dental, do uso de enxaguantes bucais e escovação da língua. Convém ressaltar que houve predomínio do uso de prótese em homens na faixa $\geq 50$ anos, o que os isenta da prática do uso de fio dental, todavia precisam ampliar a frequência de escovação. Por sua vez, trabalhadores jovens com maior escolaridade usavam fio dental, enxaguantes bucais, realizavam escovação apropriadamente, trocavam a escova em intervalos de até 3 meses, apesar de não pertencerem à categoria de maior renda.

A análise quanto aos hábitos de higiene possibilitou compreender as fragilidades desses homens em prevenir doenças decorrentes de alteraçôes da saúde bucal, identificando que medidas preventivas, atualmente mais acessíveis, ainda não estão presentes nas práticas de higienização oral.

Esses hábitos indicam maiores chances para desenvolvimento de placa bacteriana e, consequentemente, cárie dentária, pois a escovação dos dentes e o uso de fio dental são fatores de proteção bucal fundamentais e reduzem o potencial de virulência e sangramento gengival ${ }^{14}$, sendo considerados métodos efetivos e de baixo custo, capazes de atuar na ocorrência de lesōes de cáries e de doença periodontal ${ }^{15}$. Agentes antimicrobianos aplicados profissionalmente ou sob forma de dentifrícios e soluções de bochecho podem reduzir a incidência de cáries mediante controle da formação de placa, supressão de espécies cariogênicas ou inibição do metabolismo bacteriano ${ }^{16}$.

Os homens na faixa etária de 40-49 anos e os mais jovens faziam um consumo moderado de doces e refrigerantes, em menor frequência que os homens na faixa etária $\geq 50$ anos. Tanto escolaridade como renda náo influenciaram a ingestão de doces. Em relação ao consumo de frutas/legumes, os entrevistados na faixa $\geq 50$ anos consumiam maior proporção desses alimentos do que os trabalhadores mais jovens, contudo na amostra havia um baixo número de pessoas nessa faixa etária. Interessante observar que na faixa de 40-49 anos, que concentrou o maior número dos entrevistados, houve o menor percentual de ingestão de frutas e legumes.

Identifica-se a necessidade de fortalecer o consumo de alimentos saudáveis para proteção da saúde bucal. Observou-se diferenças entre hábitos alimentares e de higiene nas faixas etárias. Fica a seguinte indagação: tais diferenças podem estar relacionadas ao gênero masculino ou às características da população estudada? Novas pesquisas podem auxiliar na compreensão da singularidade masculina.

Os entrevistados pouco realizavam o autoexame bucal, método simples e extremamente eficaz na busca de sinais precoces de doenças. O autoexame deveria ser ensinado sistematicamente nos programas educativos e campanhas de esclarecimento à população, em linguagem fácil e acessível, contribuindo assim para a ampliação da cura e controle dessas doenças ${ }^{17}$.

A consulta ao cirurgião dentista compóe uma medida eficaz para a saúde bucal, pois quando há periodicidade adequada, o profissional tem a oportunidade de promover açóes de prevenção, promoção, cura e reabilitação da saúde bucal, estimulando assim o autocuidado.

Quando comparados com o sexo feminino, Travassos ${ }^{18}$ constatou que mulheres, sem restrição de atividades, integrantes de famílias de maior poder aquisitivo, de famílias com provedor de maior escolaridade e de famílias "chefiadas" por homens apresentaram maior chance de consumo de serviços preventivos e de acompanhamento ${ }^{18}$. Porém, Watson ${ }^{19}$ encontrou uma considerável falta de conscientização sobre saúde bucal entre mulheres de baixa renda, que pode estar associada às condiçôes dentárias precárias dessas mulheres ${ }^{19}$. Ostberg ${ }^{20}$ sinaliza que as meninas percebem sua saúde bucal como boa mais que os meninos, exceto no que diz respeito à aparência dos dentes ${ }^{20}$.

Algumas limitaçôes do presente estudo: não realização do cálculo amostral para encontrar de forma segura todas as variáveis estudadas, o número de pessoas obtido em alguns segmentos foi menor do que o necessário e isso reduziu o poder dos testes estatísticos, como no caso do baixo percentual de pessoas analfabetas (apenas 4), o que pode levar a distorções na interpretação. Também identificou-se que a maioria dos homens acima de 50 anos fazia uso de próteses parciais ou totais e, desse modo, a questáo sobre a presença de cáries deveria ser realizada apenas com pessoas com dentes naturais. 


\section{Conclusão}

O percurso metodológico escolhido permitiu analisar a influência das variáveis sociais e econômicas na saúde bucal masculina, bem como atender os aspectos éticos de privacidade para responder os questionários. A coleta de dados foi favorecida por ter sido realizada no local de trabalho. Possibilitou compreender os limites e potencialidades dos homens no cuidado da saúde bucal, assim como salientar a necessidade de pesquisas que abordem questóes de gênero.

Para além de identificar significados estatísticos, as associaçôes encontradas entre variáveis sociodemográficas, hábitos de higiene e conhecimento sobre saúde bucal coincidem com a prática clínica odontológica, uma vez que os entrevistados vivenciaram práticas odontológicas com pouca ênfase na preservação dentária.

Esta pesquisa pode contribuir para as práticas dos profissionais da APS no sentido de abordar os homens no momento da anamnese odontológica, sensibilizando-os quanto aos fatores de risco e proteção da saúde bucal, de forma a introduzir novas práticas de cuidado. Considerou-se uma estratégia válida a divulgação deste estudo para os gestores municipais, com vistas a qualificar as tomadas de decisôes referentes à saúde bucal.

A análise dos dados sinaliza a necessidade de investimentos em açôes de educação em saúde para a manutenção de práticas saudáveis de saúde bucal e enfatiza a necessidade de ampliar o acesso aos serviços odontológicos, estabelecer políticas para direcionar recursos, introduzir avanços tecnológicos e instituir estratégias diferenciadas para pessoas de baixo nível socioeconômico.

\section{Referências}

1. Brasil. Conselho Nacional de Secretários de Saúde. Para entender a gestão do SUS. Brasília: CONASS; 2003. p. 248. [acesso em 2009 Ago 18]. Disponível em: http://bvsms.saude.gov.br/bvs/publicacoes/para_entender_gestao.pdf

2. Gomes R. Os homens cuidam pouco da saúde. Radis. 2008; 74: 10.

3. Figueiredo W. Assistência à saúde dos homens: um desafio para os serviços de atenção primária. Ciênc Saúde Coletiva. 2005; 10(1): 105-9. http:// dx.doi.org/10.1590/S1413-81232005000100017

4. Pinheiro RS, Torres TZG. Uso de serviços odontológicos entre os Estados do Brasil. Ciênc Saúde Coletiva. 2006; 11(4): 999-1010. http://dx.doi. org/10.1590/S1413-81232006000400021

5. Brasil. Ministério da Saúde. Saúde Bucal. Brasília: Ministério da Saúde; 2006. p. 92.

6. Rank RCIC, Rank MS, Dib JE. Dificuldades maternas quanto ao uso do fio dental em crianças. Publ UEPG Ciênc Biol Saúde. 2006; 12(3): 31-8.

7. Guedes-Pinto AC, Bonecker M, Rodrigues CRMD. Fundamentos de odontología: odontopediatria. São Paulo: Editora Santos; 2009.446 p.

8. Associação Brasileira de Odontologia de Promoção de Saúde - Aboprev. Promoção de Saúde Bucal. Rio de Janeiro: Artes Médicas; 1997.

9. Panzeri H, Lara E, Zaniquelli O, Schiavetto F. Avaliação de algumas características das escovas dentais do mercado nacional. Rev Assoc Bras Odontol. 1993; 1(1): 23-9.

10. Montenegro FLB, Marchini L, Leite JÁ, Manetta CE. Tipificando e classificando os limpadores linguais no mercado brasileiro. Rev EAP/ APCD. 2006; 8(1): 12-5. [acesso em 2012 Mar 30]. Disponível em: http://www.proteseodontologica.odo.br/fbrunetti/limpadoreslinguais.htm

11. Navas EAFA, Inocêncio AC, Jorge AOC, Koga-Ito CY. Avaliação da utilização de limpador de língua na reduçãodos níveis de leveduras na cavidade bucal. Rev Odontol UNESP. 2009; 38(2): 99-103.

12. Philipp ST, Latterza AR, Cruz ATR, Ribeiro LC. Pirâmide alimentar adaptada: guia para a escolha dos alimentos. Rev Nutr.1999;12(1):65-80.

13. Mendes ML, Mendes CL, Rocha ML. Avitaminoses e suas manifestações bucais. Int J Dent. 2003; 2(2): 257-61.

14. Abegg C. Hábitos de higiene bucal de adultos porto-alegrenses. Rev Saúde Pública. 1997; 31(6): 586-93. http://dx.doi.org/10.1590/S003489101997000700007

15. Rimondini L, Zolfanelli B, Bernardi F, Bez C. Self-preventive oral behavior in an Italian University student population. J Clin Periodontol. 2001; 28(3): 207-11. http://dx.doi.org/10.1034/j.1600-051x.2001.028003207.x

16. Gonçalves NCLAV, Valsecki Junior A, Salvador SLS, Bergamo GC. Efeito de soluções fluoretadas contendo xilitol e sorbitol no número de estreptococos do grupo mutans na saliva de seres humanos. Rev Panam Salud Pública. 2001; 9(1): 30-4. http://dx.doi.org/10.1590/S1020-49892001000100007

17. Thomaz EBAF, Cutrim MCFN, Lopes FF. A importância da educação como estratégia para prevenção e diagnóstico precoce do câncer oral. Acta Oncol Bras. 2000; 20(4): 149-52.

18. Travassos C, Viacava F, Pinheiro R, Brito A. Utilização dos serviços de saúde no Brasil: gênero, características familiares e condição social. Rev Panam Salud Publica. 2002; 11(5-6): 365-73. http://dx.doi.org/10.1590/S1020-49892002000500011

19. Watson MR, Gibson G, Guo I. Women's oral health awareness and care-seeking characteristics: a pilot study. J Am Dent Assoc. 1998; $129(12): 1708-1716$.

20. Ostberg Al, Halling A, Lindblad U. A gender perspective of self-perceived oral health in adolescents: associations with attitudes and behaviours. Community Dent Health. 2001; 18(2): 110-116. 


\section{Anexo 1}

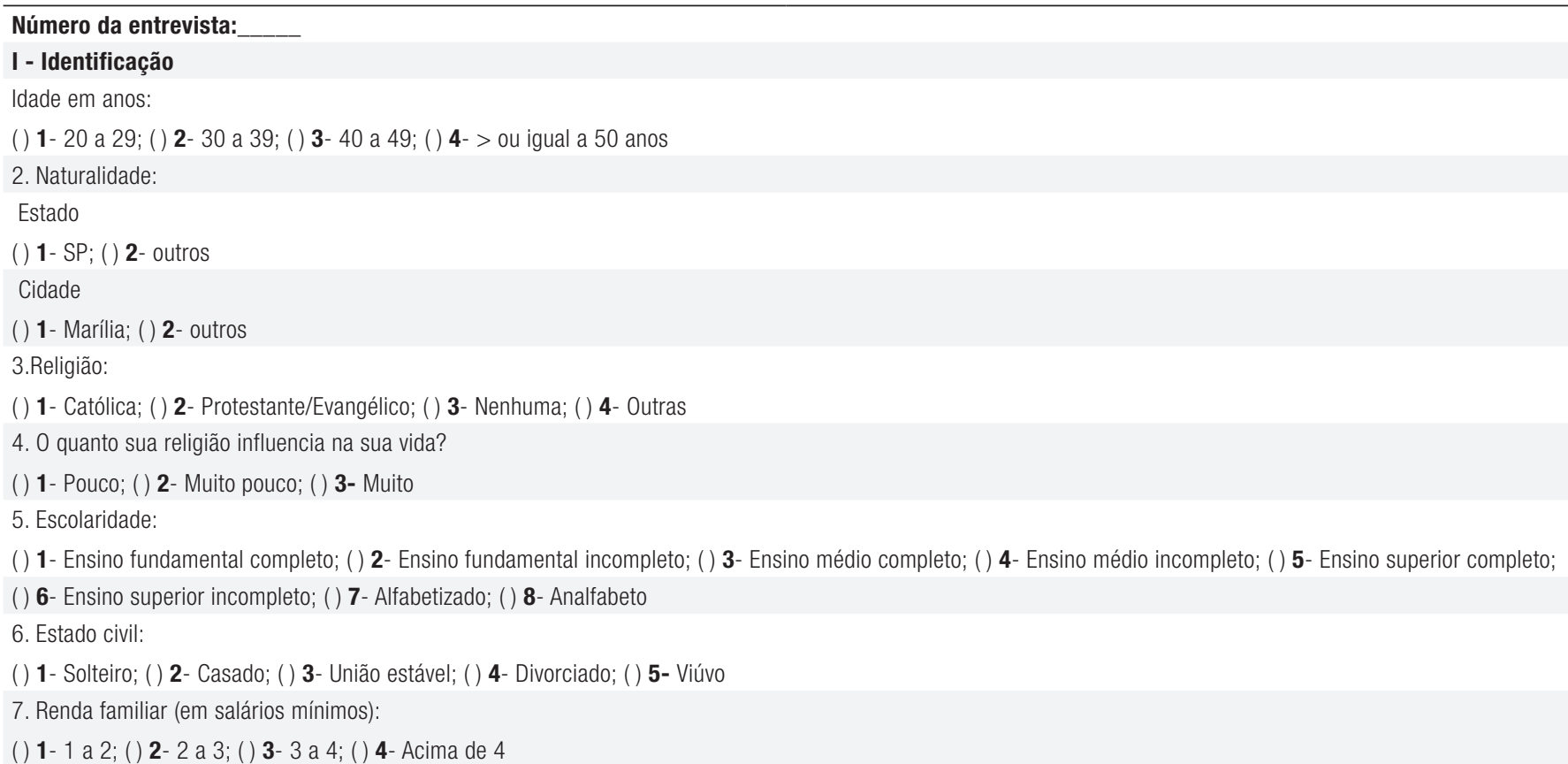

8. Profissão/Ocupação:

() 1-Serviços gerais; ( ) 2-Auxiliar administrativo; ( ) 3- Outros

\section{II - Conhecimentos sobre saúde bucal}

Com que frequência você consume doces?

() 1- 1 a 2 vezes por semana; ( ) 2- 3 a 4 vezes por semana; ( ) 3- 5 a 6 vezes por semana; ( ) 4-Diariamente; ( ) 5- Nunca Com que frequência você consome frutas, verduras e legumes?

( ) 1- 1 a 2 vezes por semana; () 2- 3 a 4 vezes por semana; () 3- 5 a 6 vezes por semana;

() 4- Diariamente; ( ) 5- Nunca

Com que frequência você consome refrigerantes e sucos artificiais?

() 1- 1 a 2 vezes por semana; ( ) 2- 3 a 4 vezes por semana; ( ) 3- 5 a 6 vezes por semana; ( ) 4- Diariamente; ( ) 5- Nunca Com que frequência você escova os dentes?

() 1- Nunca; ( ) 2- 1 a 2 vezes ao dia; ( ) 3- 3 a 4 vezes ao dia; ( ) 4- 5 ou mais vezes ao dia; () 5- 3 vezes na semana; () 6- 1 vez na semana Que tipo de escova dental você utiliza?

( ) 1- Extra macia; ( ) 2- Macia; ( ) 3- Média; ( ) 4- Dura; ( ) 5- Qualquer uma delas Com que frequência você troca sua escova dental?

( ) 1- 1 vez ao mês; ( ) 2- De 2 em 2 meses; ( ) 3- De 3 em 3 meses; ( ) 4- A cada 6 meses; ( ) 5- 1 vez ao ano Com que frequência você utiliza o fio dental?

() 1- 1 a 2 vezes por semana; () 2- 3 a 4 vezes por semana; () 3- 5 a 6 vezes por semana; ( ) 4-Diariamente; () 5- Nunca Com que frequência você utiliza enxaguantes bucais? () 1- 1 a 2 vezes por semana;

() 2- 3 a 4 vezes por semana; ( ) 3- 5 a 6 vezes por semana; ( ) 4- Diariamente;

() 5- Nunca

Com que frequência você escova a língua?

() 1- Nunca; ( ) 2- 1 a 2 vezes ao dia; ( ) 3- 3 a 4 vezes ao dia; ( ) 4- 5 ou mais vezes ao dia; ( ) 5- 3 vezes na semana; ( ) 6- 1 vez na semana Com que frequência você procura o dentista?

( ) 1-Menor que 6 meses; ( ) 2-Entre 6 meses e 1 ano; ( ) 3- Maior que 1 ano; ( ) 4- Nunca Você já apresentou ou apresenta algum/ns desses problemas bucais?

() 1- Cárie; ( ) 2-Problemas periodontais; ( ) 3-Aftas, estamatites; ( ) 4- Herpes; ( ) 5- Bruxismo Você tem hábito de:

() 1- Roer as unhas; ( ) 2-Chupar dedos; ( ) 3- Morder os lábios; ( ) 4- Não tenho nenhum desses hábitos Se sim, por quanto tempo você permanece com a mesma prótese?

() 1- Menos de 1 ano; () 2- Menos de 5 anos; () 3- Entre 5 a 10 anos; () 4- Mais de 10 anos 


\section{Anexo 1. Continuação...}

Você faz uso de algum tipo de prótese dentária?

( ) 1-Sim; ( ) 2- Não

Você considera a cárie dental uma doença transmissível?

( ) 1- Sim; ( ) 2- Não

Cada membro de sua família faz uso individual da escova dental?

( ) 1- Sim; ( ) 2- Não

Problemas bucais podem causar repercussões sistêmicas?

( ) 1- Sim; ( ) 2- Não

Você respira pela boca?

( ) 1- Sim; ( ) 2- Não

Você é fumante?

( ) 1- Sim; ( ) 2- Não

Você faz uso de bebida alcoólica?

( ) 1- Sim; ( ) 2- Não 